Old Dominion University

ODU Digital Commons

Psychology Faculty Publications

Psychology

$1-2018$

\title{
Cultural Stressors, Identity Development, and Substance Use Attitudes Among Hispanic Immigrant Adolescents
}

Timothy J. Grigsby

Myriam Forster

Alan Meca

Old Dominion University

Byron L. Zamboanga

Seth J. Schwartz

See next page for additional authors

Follow this and additional works at: https://digitalcommons.odu.edu/psychology_fac_pubs

Part of the Psychology Commons, Public Health Commons, and the Social Work Commons

\section{Repository Citation}

Grigsby, Timothy J.; Forster, Myriam; Meca, Alan; Zamboanga, Byron L.; Schwartz, Seth J.; and Unger, Jennifer B., "Cultural Stressors, Identity Development, and Substance Use Attitudes Among Hispanic Immigrant Adolescents" (2018). Psychology Faculty Publications. 22.

https://digitalcommons.odu.edu/psychology_fac_pubs/22

\section{Original Publication Citation}

Grigsby, T. J., Forster, M., Meca, A., Zamboanga, B. L., Schwartz, S. J., \& Unger, J. B. (2018). Cultural stressors, identity development, and substance use attitudes among Hispanic immigrant adolescents. Journal of Community Psychology, 46(1), 117-132. doi:10.1002/ jcop. 21920 
Authors

Timothy J. Grigsby, Myriam Forster, Alan Meca, Byron L. Zamboanga, Seth J. Schwartz, and Jennifer B. Unger 


\title{
Cultural stressors, identity development, and substance use attitudes among Hispanic immigrant adolescents
}

\author{
Timothy J. Grigsby ${ }^{1}$ (D) | Myriam Forster ${ }^{2}$ | Alan Meca $^{3}$ | \\ Byron L. Zamboanga $^{4}$ | Seth J. Schwartz ${ }^{5}$ Jennifer B. Unger ${ }^{6}$
}

\author{
${ }^{1}$ University of Texas at San Antonio, USA \\ ${ }^{2}$ California State University, Northridge, USA \\ ${ }^{3}$ Old Dominion University, USA \\ ${ }^{4}$ Smith College, USA \\ ${ }^{5}$ Leonard M. Miller School of Medicine, Univer- \\ sity of Miami, USA \\ ${ }^{6}$ University of Southern California, USA \\ Correspondence \\ timothy.grigsby@utsa.edu \\ Preparation of this article was supported by Grant \\ DA026594 from the National Institute on Drug \\ Abuse (NIDA) to Seth J. Schwartz. NIDA had no \\ role in the preparation or decision to submit this \\ work for publication.
}

\begin{abstract}
The goal of this investigation was to determine whether various cultural stressors (bicultural stress, perceived discrimination, and perceived negative context of reception [PNCR]) predict positive and negative substance use attitudes, directly and indirectly through personal identity, in a sample of immigrant Hispanic adolescents. Data on cultural stressors, substance use attitudes, and covariates were collected from 302 Hispanic immigrant adolescents (152 from Miami [61\% Cuban] and 150 from Los Angeles [70\% Mexican]) at 3 time points. PNCR was associated with identity confusion $(\beta=.175$, $\mathrm{p}=.033$ ). Identity confusion significantly predicted higher positive attitudes toward alcohol and other drug (AOD; $\beta=.216, p<.001$ ) and cigarette use $(\beta=.191, \mathrm{p}=.015)$ and mediated the relationship between PNCR with unfavorable AOD attitudes ( $\beta=-.019,95 \%$ confidence interval $[\mathrm{Cl}][-0.052,-0.001])$ and favorable AOD attitudes ( $\beta=0.038,95 \% \mathrm{Cl}[0.003,0.086])$. Perceptions of a negative context of reception may hinder successful personal identity formation and impact health outcomes for immigrant youth.
\end{abstract}

\section{1 | INTRODUCTION}

The experience of external (e.g., discrimination, context of reception) and internal (e.g., bicultural stress) cultural stressors have been shown to affect Hispanic immigrant adolescents' psychological and behavioral health beyond general measures of life stress (Berry, Kim, Minde, \& Moke, 1987; Romero \& Roberts, 2003). Theoretically, the self-medication hypothesis (Khantzian, 1997) suggests that stress exposure can increase risk for maladaptive coping strategies, such as cigarette and alcohol and other drug (AOD) use, and from a social exclusion perspective, individuals who are excluded from "mainstream" society may engage in deviant or risky behavior to cope with marginalization (Peake, Dishion, Stormshak, Moore, \& Pfeifer, 2013) or gain acceptance (Ali, Amialchuk, \& Nikaj, 2014). Studies have demonstrated that the longer immigrant youth reside in the United States, the risk for negative health outcomes increases 
(Garcia Coll \& Marks, 2009) and that risk may vary as a function of demographic characteristics (e.g., gender, generation, documentation status) or cultural factors (e.g., acculturative stress; Teruya \& Bazargan-Hejazi, 2013).

Yet the relationship between attitudes toward drug use and cultural stressors remains understudied. This is especially pertinent given that immigration is projected to be a primary source of Hispanic population growth through the middle of this century (Colby \& Ortman, 2014), and that components of substance use attitudes such as motives (i.e., the reason for using a drug) and expectancies (i.e., the anticipated effect of a drug) play an important role in predicting substance use behavior (Kuntsche, Wiers, Janssen, \& Gmel, 2010; Lee, Neighbors, \& Woods, 2007).

The theory of planned behavior (Ajzen \& Fishbein, 2000) places attitudes (i.e., a person's evaluation of performing a behavior) in a central position to influence behavioral outcomes. Results from a recent meta-analysis on the role of identity vis-à-vis the theory of planned behavior (Rise, Sheeran, \& Hukkelberg, 2010) suggests that identity explained an additional $9 \%$ of variability in health behaviors when controlling for past behavior and other components of the theory (e.g., social norms, intentions). Positive substance use attitudes (e.g., smoking or drinking fits in with the kind of life one wants) have been investigated as both a direct and indirect predictor of AOD use (Morgenstern, Isensee, Sargent, \& Hanewinkle, 2011; Puente, Gutierrez, Abellan, \& Lopez, 2008), which suggests that attitudes play a central role in the formation of intentions to use drugs and in drug use behavior (Barkin, Smith, \& Durant, 2002; Patrick \& Schulenberg, 2014).

Previous research has found that AOD use and negative health behaviors, differ between U.S.-born and non-U.S.born Hispanic groups. For example, U.S.-born youth report greater alcohol use than foreign-born Hispanics (Bacio, Mays, \& Lau, 2013), though the longer immigrant youth reside in the United States, the risk for negative health outcomes increases (Garcia Coll \& Marks, 2009). Currently, the majority of research on the relationship between cultural factors and substance use has been based on samples of U.S.-born Hispanic participants or focuses on one specific cultural factor (Donovan et al., 2012; Okamoto, Ritt-Olsen, Soto, Baezconde-Garbanati, \& Unger, 2009; Pascoe \& Smart-Richman, 2009; Romero, Carvajal, Valle, \& Orduna, 2007; Romero, Martinez, \& Carvajal, 2007), but more work is needed to inform primary prevention programs targeting immigrant youth at risk for negative health outcomes such as substance use initiation and escalation.

Unidimensional cultural constructs and broad measures of acculturation have been examined in relation to substance use initiation (Grigsby, Forster, Soto, \& Unger, 2017) and continued use (Prado, Szapocznik, Maldonado-Molina, Schwartz, \& Pantin, 2008) among Hispanics; however, the influence of specific cultural factors on AOD attitudes among immigrant Hispanic samples remains scant. Recent research has demonstrated that cultural influences work in concert rather than in isolation (Cano et al., 2015; Flay, Snyder, \& Petraitis, 2009), but empirical evidence is limited and further replication among immigrant samples.

Immigrants face many sources of stress related to the transition from a heritage country to a host county including, but not limited to, language preference and adaptation, value conflict, parent-child acculturation gaps (child's level of acculturation/adaptation over and above that of the parent), and discrimination/racism. The goal of the present investigation is to explore the unique pathways between three cultural stressors (bicultural stress, perceived discrimination, or perceived negative context of reception) with cigarette and AOD attitudes in a sample of immigrant Hispanic adolescents, as well as whether such associations are mediated by identity processes (coherence and confusion). Stress is conceptualized as any psychological, physical, or situational demand that strains an individual's capacity to cope effectively (Lazarus, 1997), whereas cultural stress is defined here as synonymous to acculturative stress-the psychological impact of adapting to a new culture. In the following subsections, we provide a review of specific cultural stressors and a theoretical framework to explain how these stressors would influence substance use outcomes through personal identity processes.

\subsection{Cultural stressors}

\subsection{1 | Perceived discrimination}

Perceived discrimination, the belief that one is treated unfairly because of one's ethnic (or other social) group membership, is positively and prospectively associated with substance use attitudes and behaviors among U.S.-born (Okamoto 
et al., 2009; Tran, Lee, \& Burgess, 2010) and immigrant (Kulis, Marsiglia, \& Nieri, 2009) Hispanic youth. Although discrimination can originate from other "Hispanic" (Córdova \& Cervantes, 2010) and ethnic groups, most discrimination measures (including the measure used in the present study) refer to general experiences of exclusion or persecution-assumed to be perpetrated by members of the dominant ethnic group in a given society (e.g., White Americans).

A key limitation in research on the role of perceived discrimination in negative health attitudes and behaviors is that discrimination is often examined independently of other types of cultural stressors (Pascoe \& Smart Richman, 2009). Discrimination is inherently linked to the context of reception within a given community and with pressures to adhere to the values and behaviors of the dominant culture (at the same time as the heritage-cultural community expects immigrants to retain their heritage values and behaviors; Romero \& Roberts, 2003). Therefore, it is important to examine perceived discrimination along with these external and internal cultural stressors to test the unique effects of discrimination. Here, we examine two additional cultural stressors: perceived negative context of reception and bicultural stress.

\subsubsection{Perceived negative context of reception}

Recent work has broadly defined "context of reception" as the social and economic opportunities available to, as well as openness or hostility expressed by a local community toward an immigrant group (Portes \& Rumbaut, 2007; Schwartz, Unger, Zamboanga, \& Szapocznik, 2010). We define negative context of reception as feeling unwelcome or the perception that one is not afforded the same opportunities compared to individuals who are either established in the United States or come from other immigrant groups. Context of reception differs from perceived discrimination as the former assesses general perceptions of an ethnic group's status in the host society, while the latter asks participants to express whether they perceive negative social interactions as being the result of ethnic or cultural discrimination.

The sociopolitical perceptions toward immigration in a receiving country, region, or community where a person or group settles may represent another important, but more distal, cultural stressor encountered while adapting to a new environment (Zhou \& Xiong, 2005). As suggested by Schwartz and colleagues (2014), an immigrant adolescent's perception of the receiving culture depends on a combination of environmental conditions s/he encounters in the new country. Among Hispanics, Mexicans and Puerto Ricans are often marginalized, whereas Cubans generally fare well, especially in Miami (Stepick \& Stepick, 2002). The revised Cuban Adjustment Act is an example of a unique opportunity extended to Cuban immigrants that is not afforded to other Hispanic subgroups and likely has an impact on their subsequent economic and general life success in the United States.

While negative context of reception has not been independently investigated in relation to substance use outcomes, it has been previously linked to conduct problems after adjusting for bicultural stress (Forster et al., 2014). The host society's receptivity to immigrants from all, or specific, ethnic backgrounds can influence immigrant children's current and future expectations, stress levels, and health behaviors.

\subsection{3 | Bicultural stress}

Bicultural stress represents the cognitive appraisal of stress related to the conflict stemming from balancing two cultural streams simultaneously (Romero \& Roberts, 2003). Most research on bicultural stress has focused on mental health outcomes (LaFromboise, Coleman, \& Gerton, 1993; Love \& Buriel, 2007; Romero, Carvajal, Valle, \& Orduña, 2007; Wei et al., 2010), yet there is also some evidence that suggests a positive relationship between bicultural stress and frequency of alcohol and drug use (Oshri et al., 2014; Romero et al., 2007). However, these studies have either used U.S.-born samples of Hispanic adolescents or have not examined the role of bicultural stress in conjunction with other cultural stressors-though more researchers are beginning to examine the combined influence of cultural stress (Cano et al., 2015; Schwartz et al., 2015). Previous work with the present sample using identity confusion and tension reduction beliefs as mediators have suggested that bicultural stress is indirectly, prospectively, and positively associated with reporting future drunkenness (Oshri et al., 2014). 


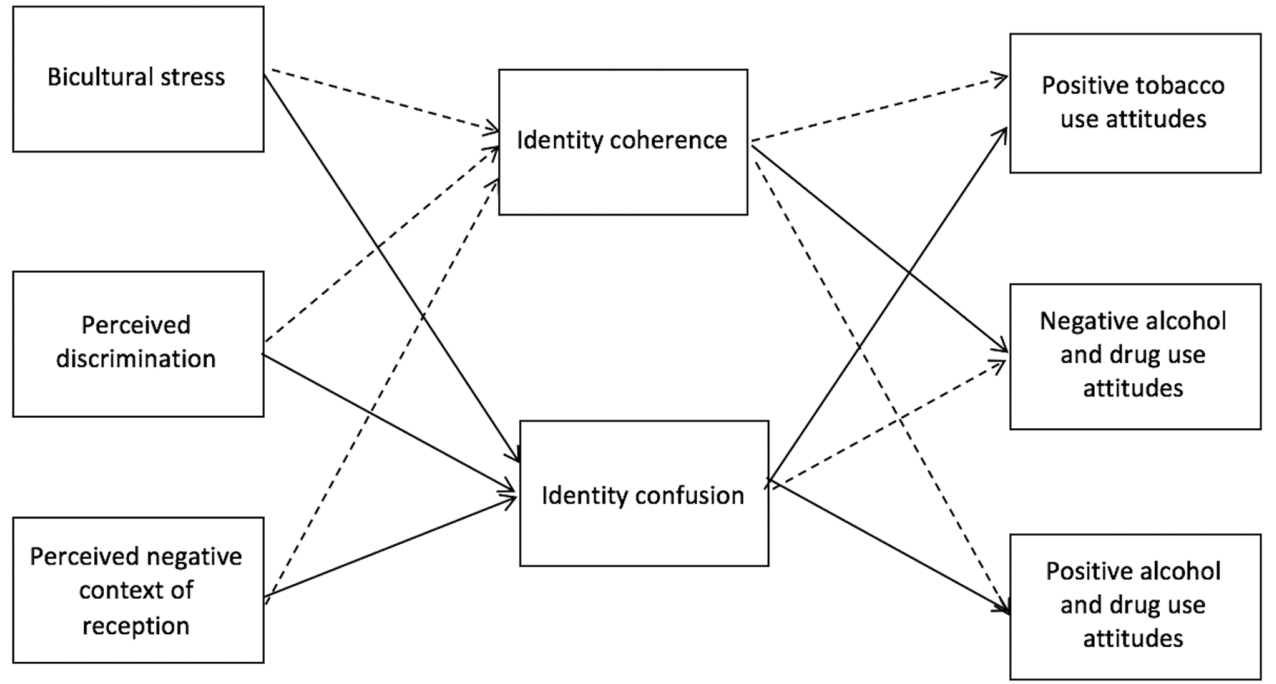

FIGURE 1 Analytical structural equation model depicting hypothesized indirect effects of cultural stressors on substance use attitudes with identity coherence and identity confusion as mediators.

Note. Positive tobacco use attitudes are depicted as an observed variable as the construct was measured with a single item. Solid lines indicate hypothesized positive associations and dashed lines indicate hypothesized negative associations. Only variables of interest are presented

\subsection{Culture and substance use attitudes: The role of personal identity}

We propose personal identity as a mechanism through which cultural stressors affect substance use attitudes (Figure 1). Identity is conceptualized as the way in which one views oneself as well as one's perceived "place" within society (Erikson, 1959). During adolescence-and especially in early and middle adolescence-identity is a process of exploration and commitment (development) rather than a goal of individualization (formation; e.g., Schwartz, Pantin, Prado, Sullivan, \& Szapocznik, 2005). As such, we use the constructs of identity coherence and confusion (Rosenthal, Gurney, \& Moore, 1981) in the present study. Identity coherence represents the extent to which one has a clear sense of direction in one's life, whereas identity confusion represents the extent to which one feels lost or hopeless (Erikson, 1959). In line with Erikson's theorizing, Schwartz, Zamboanga, Wang, and Olthuis (2009) established that identity coherence and confusion are not complete opposites in that young people can be sure of themselves in some ways and confused in others. As a result, both coherence and confusion are important mechanisms to examine in the link between cultural stressors and substance use attitudes.

The role of personal identity is a theoretical link that warrants further exploration in the association between exposure to cultural stress with cigarette and AOD attitudes (Erikson, 1959; Oshri et al., 2014; Schwartz, Zamboanga, Luyckx, Meca, \& Ritchie, 2013). Exposure to cultural stressors, the pressure inherent in navigating a new destination society, and fluctuating acculturation processes all likely impact the development of personal identity among immigrant youth (Schwartz, Montgomery, \& Briones, 2006). Specifically, experiences with external cultural stressors (e.g., perceived discrimination and negative context of reception) could potentially impede identity coherence and facilitate identity confusion as adolescents struggle to understand where they "fit in" within their families and communities. Environmental and social stressors can distract adolescents from developing their self-identity (Szabo \& Ward, 2015), but it is not clear whether cultural stressors impact identity formation among immigrant youth, and how these processes then impact cigarette or AOD attitudes. In adolescents, higher levels of identity confusion-or lower levels of identity coherence-may lead to an increased risk for experimentation with alcohol or drug use and other risky behaviors (Oshri et al., 2014; Schwartz et al., 2015). 


\section{3 | Current study and hypotheses}

Understanding the sociocultural antecedents that shape attitudes in immigrant populations may be informative for developing targeted primary prevention programs, because previous research has found that attitudes are often resistant to change and require more than simply increasing knowledge about the harms of substance use (Barkin et al., 2002). Although research has indicated that positive attitudes toward AOD are influenced by internal and external factors such as sensation seeking (Puente et al., 2008), exposure to media or via one's social network (Barkin et al., 2002; Morgenstern, Isensee, Sargent, \& Hanewinkel, 2011), and parental approval of substance use (Sherman, Chassin, Presson, Seo, \& Macy, 2009), considerably less research has focused on the role of ethnic/racial cultural factors in fostering positive attitudes toward AOD.

The present study was guided by two primary objectives. First, we aimed to identify factors that contribute to positive and negative cigarette and $A O D$ attitudes that might be leveraged in intervention programs for immigrant Hispanic youth. Second, we wanted to compare distinct, but related, cultural stressors within the same statistical model to determine if they have unique direct and/or mediated effects on later substance use attitudes (Figure 1). We hypothesized that:

H1: Higher levels of bicultural stress, perceived discrimination, and perceived negative context of reception at Time 1 will be negatively associated with identity coherence in Time 2 and, in turn, identity coherence will be (a) negatively associated with greater positive cigarette and AOD attitudes and (b) positively associated with higher negative AOD attitudes at Time 3.

H2: Bicultural stress, perceived discrimination, and perceived negative context of reception will predict higher levels of identity confusion in Time 2 and, in turn, identity confusion will be (a) positively related to greater positive cigarette and AOD attitudes and (b) negatively related to higher negative AOD attitudes at Time 3.

H3: Self-identity processes (coherence and confusion) would at least partially mediate the relationship between cultural stressors and positive or negative cigarette and AOD attitudes.

\section{2 | METHOD}

\section{1 | Participants}

The current sample comprised 302 adolescents (53\% boys; mean $[\mathrm{M}]_{\text {age }} 14.51$ years at baseline; standard deviation $[S D]=0.88$ years) who participated in COPAL (Construyendo Oportunidades Para Adolecentes Latinos), a longitudinal study of acculturation, cultural stressors, and health behaviors among recently arrived ( $<5$ years) Hispanic immigrant adolescents and their families in Miami and Los Angeles. Participants from Los Angeles $(n=150)$ were predominantly Mexican (70\%) and had resided in the United States for a median of 3 years (interquartile range [IQR] = 1-4 years), and participants from Miami $(n=152)$ were predominantly Cuban (61\%) and had resided in the United States for a median of 1 year (IQR $=0-3$ years). Data analyzed in the present study came from the first three waves of data collection (baseline, 6-8 months later and 12-14 months after baseline; described as Time 1, Time 2, and Time 3, respectively).

\section{2 | Procedures}

Given that recent Hispanic immigrants tend to reside in heavily Hispanic areas (Kasinitz et al., 2008; Stepick, Grenier, Castro, \& Dunn, 2003), recruitment focused on schools in Los Angeles and Miami-Dade Counties that were at least 75\% Hispanic. Participants were recruited from 13 schools meeting this criterion in Los Angeles County and 10 schools from Miami-Dade County. Adolescents were eligible to participate if they had lived in the United States for 5 years or less at baseline, if the adolescent was entering or currently enrolled in $9^{\text {th }}$ grade at baseline, and if the family intended to remain in the study catchment area for the three years of the study. Because most recently immigrated students 
are enrolled in English for Speakers of Other Languages (ESOL) classes, recruitment efforts were concentrated toward ESOL students and other basic English classes.

Of the 435 families who met criteria and were contacted successfully, 302 (69\%) participated. Prior to the baseline assessment, parents provided informed consent for themselves and their adolescents, and adolescents provided informed assent in a separate room to reduce the possibility that parents might influence their child's decision to participate. Ninety-two percent of the sample $(n=278)$ was retained at the second time point and $84.8 \%(n=256)$ was retained at the third time point. Los Angeles youth were more likely to drop out of the study at Times 2 and Time 3 compared to youth from Miami. An audio computer-assisted interviewing system was used to administer surveys in either English or Spanish. Most adolescents (84\%) chose to complete the Time 1 assessment in Spanish, 13\% of adolescents switched languages at Time 2, and 9.8\% changed to English between Times 2 and 3. Procedures for the study were approved by the University of Southern California and University of Miami Institutional Review Boards, and by the research review boards at the participating school districts. Additional details of study procedures can be found in Schwartz et al. (2012).

\section{$2.3 \mid$ Measures}

Unless otherwise specified, 5-point Likert scales were used for all study measures, with response options ranging from 0 (strongly disagree) to 4 (strongly agree). The range of alpha coefficients presented is drawn from the current sample across the time points and for both English and Spanish versions. Spanish versions of our study measures were developed using a two-step translation process (Sireci, Yang, Harter, \& Ehrlich, 2006), whereby measures are translated by one translator from English to Spanish, back-translated by a second translator (Spanish to English), and then evaluated by both translators to resolve discrepancies.

\subsection{1 | Demographic covariates}

For all analyses, we included gender (coded $0=$ females and $1=$ males), age at Time 1 (in years), and years in the United States at Time 1.

Perceived discrimination was measured using the seven-item Perceived Discrimination Scale (Phinney, Madden, \& Santos, 1998), which asks about the extent to which members of the receiving community have treated participants unfairly ( $\alpha=.89$; sample item: "How often do teachers or employers treat you unfairly or negatively because of your ethnic background?"). Possible responses for each item ranged from 0 (not at all) to 4 (almost always).

\subsubsection{Perceived negative context of reception (Cronbach's alpha $=.74$ )}

We used a six-item measure developed by Schwartz and colleagues (2014) that has been validated with the present sample. A sample item from the measure includes "People from my country are not welcome here."

\subsubsection{Bicultural stress (Cronbach's alpha $=.89$ )}

Romero and Roberts' (2003) 20-item Bicultural Stress Scale was designed for use with Hispanic youth. The scale assesses stress grounded in intergenerational conflict (e.g., I have to translate for my parents) and language issues (e.g., "I have been treated badly because of my accent"). The response options for each item ranged from 0 (has never happened to me) to 4 (was very stressful).

\subsection{4 | Personal identity}

Corresponding six-item subscales from the Erikson Psychosocial Stage Inventory (Rosenthal et al., 1981) were used to measure personal identity coherence ( $\alpha=.85$; sample item: "I know what kind of person I am") and confusion ( $\alpha=$.75; Sample item: "I feel mixed up"). Measurement invariance was established for the COPAL sample (Schwartz 
et al., 2015). There was a significant, negative correlation between identity coherence and confusion (Time 2: $r=-.37$, $p<.001)$.

\subsection{5 | Positive cigarette use attitudes}

Positive tobacco attitudes were assessed using a single item, "Smoking cigarettes fits with the kind of life I want to lead" (McNeal \& Hansen, 1999). Responses ranged from 0 (strongly disagree) to 4 (strongly agree). Due to the highly positively skewed response distribution, we recoded responses into a dichotomous variable, in which strongly disagree and disagree were recoded to 0 , and agree and strongly agree were recoded to 1 . Approximately $9 \%(n=22)$ of adolescents were coded as a 1 on this dichotomous variable at Time 3.

\subsubsection{AOD attitudes}

AOD attitudes at Time 3 were assessed with six items (Resnicow, Soler, Braithwaite, Selassie, \& Smith, 1999), with the response options ranging from 0 (strongly disagree) to 4 (strongly agree). A confirmatory factor analysis revealed a twofactor structure with good fit, $\chi 2(8)=20.206, p=.009$; comparative fit index $(C F I)=.932$; root mean square error of approximation $(\mathrm{RMSEA})=.071$; standardized root mean square residual $(\mathrm{SRMR})=.041$, in which three items loaded on each factor we described as positive AOD attitudes (Cronbach's alpha = .840; e.g., "Drugs do/would help me function at parties") and negative AOD attitudes (Cronbach's alpha =.609; e.g., "If I use alcohol or drugs, I will have more health problems than other people"). We also calculated and controlled for AOD attitudes at Time 1 as an additional covariate.

\section{4 | Analytic plan}

Descriptive statistics were calculated for demographic variables and measures included in the model and were compared across sites (Los Angeles and Miami). Main analyses were conducted using path analysis in Mplus (version 7.2; Muthén \& Muthén, 1998-2007) with a sandwich covariance estimator (Kauermann \& Carroll, 2001) to adjust the standard errors and account for nesting of participants within schools. We controlled for baseline levels of identity coherence and confusion, attitudes toward cigarette use, and positive and negative attitudes toward AOD use (Cole \& Maxwell, 2003) in addition to baseline age, gender, years spent in the United States, and site. All Time 1 predictors and covariates were correlated in the final model as well as the identity coherence and confusion constructs at Time 2. Intraclass correlation coefficients were explored to examine clustering in schools and ranged from $<0.01$ to 0.03 ; therefore, school clustering was not examined in the analysis. The main analyses were completed in four steps.

First, we established the empirical model by evaluating and comparing a full mediation model (through identity coherence and confusion) to a partial mediation model (in which direct paths were allowed from cultural stressors to youth's attitudes toward cigarette and drug use). Second, we evaluated the significance of the direct effects of cultural stressors on AOD attitudes. Third, we examined indirect effects (i.e., whether identity coherence and confusion mediated the relationship between cultural stress and attitudes toward cigarette and drug use). We calculated $95 \%$ indirect confidence intervals and coefficients using the RMediation package (Tofighi \& MacKinnon, 2011), which is based on the asymmetric distribution of products test (MacKinnon, 2008). Fourth, we determined whether the specified model significantly differed across site.

Model fit was evaluated using a variety of indices (Bollen \& Long, 1993). These include the $\chi^{2}$ test of model fit (which should be statistically nonsignificant, $p>.05$ ), the RMSEA, the CFI, and the SRMR. According to values suggested by Little (2013), good model fit is represented as CFI $\geq .95$, RMSEA $\leq .05$, and SRMR $\leq .05$, whereas acceptable fit is represented as CFI $=.90-.95$, and RMSEA $=.05-.08$, and SRMR $=.05-.08$. We report, but do not use, the $\chi^{2}$ value in interpreting results because it tests a null hypothesis of perfect fit, which is rarely plausible in large samples or complex models (Davey \& Savla, 2009). To compare the full versus the partial mediation models, we referenced Little's (2013) cutoffs of $\Delta \mathrm{CFI}(>.010)$ and the $\Delta$ RMSEA (> .010). Although the $\Delta \chi^{2}$ difference test is reported, because it often indicates significant differences when the fit statistics themselves are only trivially different (Cheung \& Rensvold, 2002; 
TAB LE 1 Demographic information and variables of interest for the sample presented separately by site (Los Angeles and Miami)

\begin{tabular}{|c|c|c|c|c|}
\hline & Los Angeles $n=150$ & Miami N = 152 & Difference $\left(\chi^{2}\right.$ or $\left.\mathrm{t}\right)$ & Total sample $(\mathrm{n}=302)$ \\
\hline Variable & $f(\%)$ & $f(\%)$ & & $f(\%)$ \\
\hline \multicolumn{5}{|l|}{ Gender } \\
\hline Male & 85 & 75 & 2.14 & 160 \\
\hline Female & 78 & 64 & & 142 \\
\hline $\begin{array}{l}\text { T1 Positive cigarette } \\
\text { attitudes }\end{array}$ & $17(15 \%)$ & $15(11 \%)$ & 1.04 & $32(13 \%)$ \\
\hline \multirow{2}{*}{$\begin{array}{l}\text { T3 Positive cigarette } \\
\text { attitudes }\end{array}$} & $9(8 \%)$ & $13(9 \%)$ & 0.14 & $22(9 \%)$ \\
\hline & $M(S D)$ & $M(S D)$ & & $M(S D)$ \\
\hline T1 Age (in years) & $14.57(0.95)$ & $14.44(0.79)$ & 1.29 & $14.51(0.88)$ \\
\hline $\begin{array}{l}\text { T1 Perceived } \\
\text { negative context of } \\
\text { reception }\end{array}$ & $8.91(4.52)$ & $8.55(4.96)$ & 0.67 & $8.72(4.74)$ \\
\hline $\begin{array}{l}\text { T1 Perceived } \\
\text { discrimination }\end{array}$ & $12.45(2.58)$ & $12.61(2.40)$ & 0.54 & $12.53(2.49)$ \\
\hline T1 Bicultural stress & $19.50(13.65)$ & $17.48(14.95)$ & -1.22 & $18.48(14.33)$ \\
\hline T1 Identity confusion & $9.51(4.23)$ & $9.17(4.86)$ & -0.66 & $9.33(4.55)$ \\
\hline T2 identity confusion & $9.36(4.27)$ & $9.14(5.16)$ & -0.39 & $9.24(4.75)$ \\
\hline T1 identity coherence & $18.18(3.47)$ & $19.63(3.25)$ & $3.77^{* *}$ & $18.91(3.43)$ \\
\hline T2 identity coherence & $18.25(3.51)$ & $19.02(4.32)$ & 1.64 & $18.66(3.97)$ \\
\hline $\begin{array}{l}\text { T1 Positive alcohol } \\
\text { and drug attitudes } \\
\text { (sum) }\end{array}$ & $5.57(2.66)$ & $5.06(2.98)$ & -1.56 & $5.31(2.83)$ \\
\hline $\begin{array}{l}\text { T1 Negative alcohol } \\
\text { and drug attitudes } \\
\text { (sum) }\end{array}$ & $2.13(2.13)$ & $2.24(2.13)$ & 0.44 & $2.19(2.25)$ \\
\hline $\begin{array}{l}\text { T3 Positive alcohol } \\
\text { and drug attitudes } \\
\text { (sum) }\end{array}$ & $5.10(2.85)$ & $5.06(3.72)$ & -0.09 & $5.06(3.35)$ \\
\hline $\begin{array}{l}\text { T3 Negative alcohol } \\
\text { and drug attitudes } \\
\text { (sum) }\end{array}$ & $2.58(2.43)$ & $3.11(2.50)$ & 1.69 & $2.88(2.48)$ \\
\hline
\end{tabular}

Note. $\mathrm{M}=$ mean; $\mathrm{SD}=$ standard deviation; $\mathrm{f}=$ frequency; med = median; $\mathrm{IQR}=$ interquartile range; $\mathrm{T} 1=\mathrm{Time} 1 ; \mathrm{T} 2=\mathrm{Time} 2$; T3 = Time 3 .

Values in table reflect total scores for each scale (sum of items).

${ }^{*} \mathrm{p}<0.05 .{ }^{* *} \mathrm{p}<0.01 .{ }^{* * *} \mathrm{p}<0.001$.

Meade, Johnson, \& Braddy, 2008), it was not used in our interpretations. Missing data were accounted for with use of the full information maximum likelihood algorithm in Mplus.

\section{3 | RESULTS}

\subsection{Descriptive statistics and site differences}

As shown in Table 1, on average, participants were 14.51 years old at Time $1(S D=0.88)$ and $142(47 \%)$ were female. Baseline identity coherence scores differed significantly across sites ( $t=3.77, p<0.01$ ), but no other statistically significant site differences emerged in our variables of interest. Bivariate relationships between the variables of interest are displayed in Table 2. 
TAB LE 2 Correlation matrix displaying bivariate relationships between predictors (perceived discrimination, bicultural stress, negative context of reception), mediators (identity cohesion and confusion), and outcomes (positive and negative AOD attitudes, positive cigarette attitudes)

\begin{tabular}{llllllllc} 
& PDS & BSS & PNCR & Coh. & Conf. & Pos. AOD & Neg. AOD & Pos. CIG \\
\hline PDS & - & $.54^{* * *}$ & $.61^{* * *}$ & -.07 & $0.26^{* * *}$ & $.21^{* * *}$ & .07 & $.23^{* * *}$ \\
BSS & & - & $.54^{* * *}$ & -.10 & $.38^{* * *}$ & $.26^{* * *}$ & -0.01 & $0.14^{*}$ \\
\hline PNCR & & & - & $-.18^{* *}$ & $.55^{* * *}$ & $.30^{* * *}$ & $.12^{\wedge}$ & $.32^{* * *}$ \\
Coh. & & & & - & $-.37^{* * *}$ & $-.21^{* * *}$ & .005 & $-.17^{* * *}$ \\
\hline Conf. & & & & & - & $.30^{* * *}$ & $.12^{\wedge}$ & $.25^{* * *}$ \\
Pos. AOD & & & & & - & -.03 & $.76^{* * *}$ \\
\hline Neg. AOD & & & & & & - & -.04 \\
\hline Pos. CIG & & & & & & & - \\
\hline
\end{tabular}

Note. $\mathrm{AOD}=$ alcohol and other drug; $\mathrm{PDS}=$ perceived discrimination; $\mathrm{BSS}=$ bicultural stress; $\mathrm{PNCR}=$ perceived negative context of reception; coh = identity coherence; conf = identity confusion; pos AOD = Time 3 positive AOD attitudes; neg $\mathrm{AOD}=$ Time 3 negative $\mathrm{AOD}$ attitudes; $\operatorname{pos} \mathrm{CIG}=$ Time 3 positive cigarette attitudes.

${ }^{*} \mathrm{p}<0.05 .^{* *} \mathrm{p}<0.01{ }^{* * *} \mathrm{p}<0.001 .{ }^{\wedge} \mathrm{p}=0.05 ß$.

\section{2 | Main findings}

\subsection{1 | Step 1-model specification}

Because the primary goal of the current study was to examine mediation, it was important to establish whether identity coherence and confusion fully or partially mediated the relationship between cultural stressors and youth's attitudes toward cigarette and drug use. The partial mediated model, in which direct paths between cultural stress and youth's attitudes toward cigarette and drug use were maintained, was fit first as it represented the least restrictive model. The partially mediated model provided adequate fit, $\chi^{2}(164)=287.85, p<.001 ; \mathrm{CFI}=.978$; RMSEA $=.061$; $\mathrm{SRMR}=.021$.

Next, we evaluated the full mediation model by removing the direct paths between cultural stress and youth's attitudes toward cigarette and drug use. This model fit the data adequately, $\chi^{2}(173)=295.05, p<.001 ; \mathrm{CFI}=.982$; RMSEA $=.027 ;$ SRMR $=.021$, and did not represent a significant decline in model fit from the partial mediation model, $\Delta \chi^{2}(9)=7.03, p=.342 ; \Delta \mathrm{CFI}=.004 ; \Delta \mathrm{RMSEA}=.024$. Because it represents the more parsimonious model, the full mediation model was retained.

\subsubsection{Step 2-exploration of direct effects in full mediation model}

Standardized path estimates and confidence intervals are reported in Table 3. Controlling for identity confusion at Time 1, gender, age, years in the United States, and site perceived negative context of reception predicted greater identity confusion at Time $2(\beta=.175, p=.033$ ). No other cultural stressors were significantly predictive of identity confusion or coherence. With regards to attitude toward cigarettes and drug use, identity confusion at Time 2 predicted higher positive attitudes toward drugs $(\beta=.216, p<.001)$ and cigarette use $(\beta=.191, p=.015)$, and lower negative attitudes toward drug use $(\beta=-.11, p=.031)$ at Time 3 . In addition, identity coherence at Time 2 negatively predicted positive attitudes toward drugs $(\beta=-.159, p=.049)$ and cigarette use $(\beta=-.124, p=.027)$ at Time 3.

\subsubsection{Step 3-identity coherence and confusion as a mediator of attitudes toward cigarette and $A O D$ use}

Negative context of reception at Time 1 indirectly and negatively predicted negative attitudes toward AOD at Time 3 through identity confusion at Time 2 ( $\beta=-.019, p=<0.05,95 \% \mathrm{Cl}=[-0.052,-0.001])$. Similarly, the indirect effect of negative context of reception at Time 1 on positive attitudes toward AOD on Time 3 though identity confusion at 
TAB LE 3 Observed direct effects in the final full mediation model

\begin{tabular}{|c|c|c|c|c|}
\hline Outcome & Predictor & Estimate & $S E$ & $p$-value \\
\hline \multirow[t]{4}{*}{ Coherence (T2) } & Coherence (T1) & 0.465 & 0.05 & $<0.001$ \\
\hline & Bicultural stress (T1) & -0.015 & 0.045 & 0.746 \\
\hline & Perceived discrimination (T1) & -0.004 & 0.048 & 0.831 \\
\hline & Negative context of reception (T1) & 0.051 & 0.095 & 0.596 \\
\hline \multirow[t]{5}{*}{ Confusion (T2) } & Confusion (T1) & 0.21 & 0.068 & 0.002 \\
\hline & Bicultural stress (T1) & 0.094 & 0.082 & 0.249 \\
\hline & Perceived discrimination (T1) & 0.054 & 0.091 & 0.554 \\
\hline & Negative context of reception (T1) & 0.175 & 0.082 & 0.033 \\
\hline & Positive attitudes toward drugs (T1) & 0.165 & 0.091 & 0.068 \\
\hline \multirow[t]{6}{*}{ Positive attitudes toward drugs (T3) } & Negative attitudes toward drugs (T1) & -0.117 & 0.06 & 0.049 \\
\hline & Coherence (T2) & -0.159 & 0.049 & 0.001 \\
\hline & Coherence (T1) & 0.171 & 0.072 & 0.017 \\
\hline & Confusion (T2) & 0.216 & 0.072 & $<0.001$ \\
\hline & Confusion (T1) & -0.003 & 0.062 & 0.973 \\
\hline & Positive attitudes toward drugs (T1) & -0.063 & 0.046 & 0.172 \\
\hline \multirow[t]{6}{*}{ Negative attitudes toward drugs (T3) } & Negative attitudes toward drugs (T1) & 0.108 & 0.057 & 0.061 \\
\hline & Coherence (T2) & 0.018 & 0.10 & 0.86 \\
\hline & Coherence (T1) & 0.051 & 0.124 & 0.678 \\
\hline & Confusion (T2) & -0.11 & 0.054 & 0.041 \\
\hline & Confusion (T1) & -0.004 & 0.063 & 0.954 \\
\hline & Positive attitudes toward cigarettes (T1) & -0.11 & 0.054 & 0.04 \\
\hline \multirow[t]{5}{*}{ Positive attitudes toward cigarettes (T3) } & Negative attitudes toward cigarettes (T1) & 0.112 & 0.097 & 0.247 \\
\hline & Coherence (T2) & -0.124 & 0.056 & 0.027 \\
\hline & Coherence (T1) & 0.102 & 0.063 & 0.105 \\
\hline & Confusion (T2) & 0.191 & 0.078 & 0.015 \\
\hline & Confusion (T1) & -0.098 & 0.092 & 0.286 \\
\hline
\end{tabular}

Note. SE = standard error. Standardized beta coefficients presented. Significant findings $(p<0.05)$ are indicated by bold text.

Time 2 was statistically significant $(\beta=.038, p<0.05,95 \% \mathrm{Cl}[0.003, .086])$. There was no statistically significant indirect effect for positive cigarette use attitudes.

\subsubsection{Step 4-Invariance across site}

Finally, we sought to determine whether observed relationships differed across Miami and Los Angeles. We compared an unconstrained model (with all paths free to vary across site) to a constrained model (with each path constrained to be equal across site) using the $\Delta$ CFI ( $>$.010), and the $\triangle$ RMSEA ( $>$.010) criteria (Little, 2013). There was evidence of a significant difference in fit between these two models, $\Delta \chi^{2}(18)=29.18, p=.0 .046 ; \Delta \mathrm{CFI}=.0 .025 ; \Delta \mathrm{RMSEA}<.001$. We examined each path for consistency across site by constraining one path at a time and examining the change in the log likelihood value. Results indicated that, for the Miami sample only, bicultural stress at Time 1 predicted identity coherence levels at Time 2 ( $\beta=-0.099, \mathrm{p}=0.036,95 \% \mathrm{Cl}[-0.191,-0.006])$.

Additionally, we observed that the relationship between negative context of reception at Time 1 had a positive association with identity coherence at Time $2(\beta=0.196, \mathrm{p}=0.032,95 \% \mathrm{Cl}[0.017,0.375])$ in the Miami sample, whereas it had a negative association with identity coherence at Time $2(\beta=-0.11, \mathrm{p}=0.025,95 \% \mathrm{Cl}[-0.207,-0.014])$ in the Los Angeles sample. 


\section{4 | DISCUSSION}

The goal of the present study was to examine the relationship between culturally based stressors, personal identity development, and substance use attitudes in a sample of recent immigrant Hispanic adolescents. We found direct prospective associations as well as indirect effects, suggesting that personal identity contributes to the effect of cultural stress on substance use attitudes.

Our findings suggest that identity processes mediate the effects of negative context of reception on negative substance use attitudes. Direct relationships between cultural stressors and the outcomes of interest did not improve overall model fit. While higher levels of perceived discrimination and bicultural stress are directly associated with tobacco (Romero, Carvajal, et al., 2007; Romero, Martinez, et al., 2007), AOD use (Romero et al., 2007; Schwartz et al., 2014) and substance use disorders (Salas-Wright, Clark, Vaughn, \& Cordova, 2015), the inclusion of potential mediators leading to substance use uptake has not been examined until now.

Our first and second hypotheses were only partially supported. Negative context of reception predicted greater identity confusion but not greater identity coherence. Both higher levels of identity coherence and lower levels of identity confusion were negatively related with positive attitudes toward cigarettes or AOD, a finding that is consistent with previous research (Rise et al., 2010). Our findings extend the results of Schwartz et al. (2006) by suggesting that increases in identity confusion-a feeling of being lost-represents the primary mechanism through which personal identity contributes to risky attitudes (and perhaps behaviors) among immigrant youth. It is conceivable that experiencing and attempting to mitigate cultural stress can distract immigrant youth from developing their personal identity, thereby increasing their levels of identity confusion. The mediating role of identity confusion has been documented in other studies of Hispanic immigrant youth (Oshri et al., 2014; Schwartz et al., 2005; Schwartz, Mason, Pantin, \& Szapocznik, 2009).

There was partial support for our final hypothesis. Perceived negative context of reception predicted higher levels of identity confusion in Time 2 that, in turn, was related to lower levels of negative AOD attitudes and higher levels of positive AOD attitudes at Time 3 . Our findings suggest that being poorly received by a host community can heighten levels of identity confusion and reduce negative attitudes, and increase positive attitudes toward AOD use. This could occur when immigrant youth endorse positive attitudes toward alcohol and drugs to "fit in" despite knowing that drug use can be physically harmful. However, the students in this sample were recruited from schools where the majority of students (> 75\%) identified as Hispanic. In short, the relationship between perceived negative context of reception, identity confusion, and AOD attitudes may be limited to social contexts where intragroup discrimination is more pronounced. This could potentially explain the site differences observed between the Miami and Los Angeles samples.

In and around Miami, Cuban immigrants have formed a social and economic enclave (Portes \& Puhrmann, 2015) where recent immigrants may have more local opportunities for economic and social growth, thus solidifying the coherence of their personal identity. In Los Angeles, however, the primarily Mexican-American immigrant population is dispersed and under constant perceived or real threat of deportation. A negative context of reception, as a result, may hinder the ability to understand where they belong and drugs may become a maladaptive coping mechanism. For undocumented immigrants especially, alcohol or drug use may be the only available resource from escaping the stress, depression, or chronic discrimination. Further work is needed to investigate this relationship with immigrant adolescents in more ethnically heterogeneous contexts. This will allow researchers to explore how questioning one's identity may lead immigrant youth to explore social groups where substance use is prevalent and determine whether behavioral homophily can contribute to a positive sense of identity (Brechwald \& Prinstein, 2011).

Identity confusion has also been associated with an increased likelihood of alcohol initiation in Hispanic adolescents (Donovan et al., 2012; Schwartz, Mason, Pantin, \& Szapocznik, 2008), and work with this sample has evidenced an indirect relationship between cultural stressors, alcohol expectancies, and alcohol use at a later wave of data collection (Oshri et al., 2014). Previous evidence (Schwartz et al., 2011; Schwartz et al., 2017) suggests personal identity confusion is most predictive of negative and health-compromising outcomes, and less strongly predictive of healthpromoting outcomes. Such a finding may support Erikson's $(1950,1968)$ contention that a confused sense of identity 
serves as a direct risk for harmful behaviors that may interfere with one's ability to plan for the future. Prevention programs should aim to provide immigrant youth with skills to adapt to new environments, integrate into unfamiliar cultural settings, and encourage them to develop their own unique personal identities that reflect their cultural backgrounds. This can be achieved by use of a multipronged prevention approach that includes resilience training and facilitation of active coping strategies, a developmentally sound approach to promote healthy identity development, and a substance use prevention component addressing universal risk factors (e.g., peer use, depression or stress, impulsivity).

These findings have important theoretical implications in explaining the relationship between cultural stress and substance use outcomes for immigrant youth. Specifically, we observed similar bivariate relationships between the three correlated cultural stressors and substance use attitudes in this sample. However, when examining these stressors concurrently in a single statistical model, only perceived negative context of reception had a significant, prospective influence on positive and negative AOD attitudes through identity confusion. This suggests that perceived negative context of reception may be an underlying mechanism that explains associations between perceived discrimination or bicultural stress with substance use outcomes or relationships between latent "cultural stress" variables comprised of items from these three constructs (Cano et al., 2015).

Moreover, individuals in contexts they perceive as unwelcoming or threatening to their ethnic group may be more likely to report discrimination or bicultural stress, which have been observed as risk factors for substance use and other negative health outcomes. This finding is worthy of replication to highlight the potential importance of the social contexts that these immigrant groups are embedded in and how this contributes to personal levels of stress.

\section{1 | Limitations}

The reader should interpret these findings with respect to the several important limitations. First, this analysis should only be generalized to immigrant Hispanic populations with similar demographic characteristics as those in Miami and Los Angeles. Our findings may not apply to "new receiving contexts" in which Hispanic cultures are less well established. Second, we did not assess perceptions or identity development prior to immigration and therefore must limit our discussion of antecedents and consequences postimmigration. Third, data were gathered with self-report survey and may be subject to biases of self-reporting (e.g., social desirability).

Fourth, we did not have data on other empirically and theoretically relevant covariates such as peer norms, peer substance use, or legal status of participants' families. Fifth, the validity of the single item for positive cigarette attitudes is uncertain and it is possible that students may have interpreted the item differently based on their experiences with smoking. Last, we were not able explore attitudes toward specific substances, such as marijuana, and it is possible that differences in attitudes toward such substances reflect sociopolitical differences between California, where residents recently voted in favor of recreational marijuana use, and Florida, where only medical marijuana use is permitted.

\subsection{Conclusion}

Prior work suggests that the three cultural stressors investigated here may cluster onto a latent cultural stress construct reflecting a general sense of being unwanted or considered a member of an "outgroup" (Cano et al., 2015; Schwartz et al., 2015). However, the findings of the present investigation suggest that certain cultural stressors may have a greater influence on negative outcomes for Hispanic youth. Moving into communities that have negative perceptions of specific immigrant groups also appears to promote identity confusion, leading to lowered negative substance use attitudes.

There are several avenues for future work in this area. First, while we examined site differences between Miami and Los Angeles, as a proxy to capture differences between Cuban and Mexican immigrants, respectively, there is a need to examine subgroup differences within each site. For instance, do these associations persist among non-Mexican Hispanic immigrants in Los Angeles? Second, we should explore how family separation and reunification impact the experience of cultural stressors and whether these processes negatively impact health behaviors and outcomes (Suarez-Orozco, Bang, \& Kim, 2010). Intervention efforts with immigrant populations should focus on community level 
strategies to reduce culturally related stress by promoting the development of tolerant and positive environments toward immigrant youth.

\section{ORCID}

Timothy J. Grigsby (D) http://orcid.org/0000-0002-9416-4502

\section{REFERENCES}

Ajzen, I., \& Fishbein, M. (2000). Attitudes and the attitude-behavior relation: Reasoned and automatic processes. European Review of Social Psychology, 11(1), 1-33.

Ali, M. M., Amialchuk, A., \& Nikaj, S. (2014). Alcohol consumption and social network ties among adolescents: Evidence from Add Health. Addictive Behaviors, 39(5), 918-922.

Bacio, G. A., Mays, V. M., \& Lau, A. S. (2013). Drinking initiation and problematic drinking among Latino adolescents: Explanations of the immigrant paradox. Psychology of Addictive Behaviors, 27(1), 14-22.

Barkin, S. L., Smith, K. S., \& Durant, R. H. (2002). Social skills and attitudes associated with substance use behavior among young adolescents. Journal of Adolescent Health, 30, 448-454.

Berry, J. W., Kim, U., Minde, T., \& Moke, D. (1987). Comparative studies of acculturative stress. International Migration Review, 21(3), 491-511.

Brechwald, W. A., \& Prinstein, M. J. (2011). Beyond homophily: A decade of advances in understanding peer influence processes. Journal of Research on Adolescence, 21(1), 166-179.

Cano, M. Á., Schwartz, S. J., Castillo, L. G., Romero, A. J., Huang, S., Lorenzo-Blanco, E., ... Szapocznik, J. (2015). Depressive symptoms and externalizing behaviors among Hispanic immigrant adolescents: Examining longitudinal effects of cultural stress. Journal of Adolescence, 42, 31-39.

Cheung, G. W., \& Rensvold, R. B. (2002). Evaluating goodness-of-fit indexes for testing measurement invariance. Structural Equation Modeling, 9(2), 233-255.

Colby, S. L., \& Ortman, J. M. (2014). Projections of the size and composition of the US population: 2014 to 2060 . (Current Population Reports P25-1143). Washington, DC: U.S. Census Bureau.

Cole, D. A., \& Maxwell, S. E. (2003). Testing mediational models with longitudinal data: Questions and tips in the use of structural equation modeling. Journal of Abnormal Psychology, 112(4), 558-577.

Córdova, D., \& Cervantes, R. C. (2010). Intergroup and within-group perceived discrimination among US-born and foreign-born Latino youth. Hispanic Journal of Behavioral Sciences, 32(2), 259-274.

Davey, A., \& Savla, J. (2009). Estimating statistical power with incomplete data. Organizational Research Methods, 12, 320-346.

Donovan, R. A., Huynh, Q. L., Park, I. J., Kim, S. Y., Lee, R. M., \& Robertson, E. (2012). Relationships among identity, perceived discrimination, and depressive symptoms in eight ethnic-generational groups. Journal of Clinical Psychology, 69, 397-414.

Erikson, E. H. (1959). Identity and the life cycle. New York: International Universities Press.

Erikson, E. H. (1968). Youth in crisis. New York: W. W. Norton.

Flay, B. R., Snyder, F., \& Petraitis, J. (2009). The theory of triadic influence. Emerging Theories in Health Promotion Practice and Research, 2, 451-510.

Grigsby, T. J., Forster, M., Soto, D. W., \& Unger, J. B. (2017). Changes in the strength of peer influence and cultural factors on substance use initiation between late adolescence and emerging adulthood in a Hispanic sample. Journal of Ethnicity in Substance Abuse, 16(2), 137-154.

Kasinitz, P. (2008). Becoming American, becoming minority, getting ahead: The role of racial and ethnic status in the upward mobility of the children of immigrants. The Annals of the American Academy of Political and Social Science, 620, $253-269$.

Kauermann, G., \& Carroll, R. J. (2001). A note on the efficiency of sandwich covariance matrix estimation. Journal of the American Statistical Association, 96(456), 1387-1396.

Khantzian, E. J. (1997). The self-medication hypothesis of substance use disorders: A reconsideration and recent applications. Harvard Review of Psychiatry, 4, 231-244.

Kulis, S., Marsiglia, F. F., \& Nieri, T. (2009). Perceived ethnic discrimination versus acculturation stress: Influences on substance use among Latino youth in the Southwest. Journal of Health and Social Behavior, 50(4), 443-459. 
Kuntsche, E., Wiers, R. W., Janssen, T., \& Gmel, G. (2010). Same wording, distinct concepts? Testing differences between expectancies and motives in a mediation model of alcohol outcomes. Experimental and Clinical Psychopharmacology, 18(5), 436-444.

LaFromboise, T., Coleman, H. L., \& Gerton, J. (1993). Psychological impact of biculturalism: Evidence and theory. Psychological Bulletin, 114(3), 395-412.

Lazarus, R. S. (1997). Hurrah for a systems approach: Commentary on The utility of systems models of stress and coping for applied research: The case of cancer adaptation, by M. R. Somerfield. Journal of Health Psychology, 2, 158-160.

Lee, C. M., Neighbors, C., \& Woods, B. A. (2007). Marijuana motives: Young adults' reasons for using marijuana. Addictive Behaviors, 32(7), 1384-1394.

Little, T. D. (2013). Longitudinal structural equation modeling. New York: Guilford Press.

Love, J. A., \& Buriel, R. (2007). Language brokering, autonomy, parent-child bonding, biculturalism, and depression: A study of Mexican American adolescents from immigrant families. Hispanic Journal of Behavioral Sciences, 29(4), 472-491.

McNeal, R. B., \& Hansen, W. B. (1999). Developmental patterns associated with the onset of drug use: Changes in postulated mediators during adolescence. Journal of Drug Issues, 29(2), 381-400.

Meade, A. W., Johnson, E. C., \& Braddy, P. W. (2008). Power and sensitivity of alternative fit indices in tests of measurement invariance. Journal of Applied Psychology, 93(3), 568-592.

Morgenstern, M., Isensee, B., Sargent, J. D., \& Hanewinkel, R. (2011). Attitudes as mediators of the longitudinal association between alcohol advertising and youth drinking. Archives of Pediatric Adolescent Medicine, 165, 610-616.

Okamoto, J., Ritt-Olsen, A., Soto, D., Baezconde-Garbanati, L., \& Unger, J. B. (2009). Perceived discrimination and substance use among Latino adolescents. American Journal of Health Behavior, 33, 718-727.

Oshri, A., Schwartz, S. J., Unger, J. B., Kwon, J. A., Des Rosiers, S. E., Baezconde-Garbanati, L., ... Villamar, J. A. (2014). Bicultural stress, identity formation, and alcohol expectancies and misuse in Hispanic adolescents: A developmental approach. Journal of Youth and Adolescence, 43, 2054-2068.

Pascoe, E. A., \& Smart Richman, L. (2009). Perceived discrimination and health: A meta-analytic review. Psychological Bulletin, 135(4), 531-554.

Patrick, M. E., \& Schulenberg, J. E. (2014). Prevalence and predictors of adolescent alcohol use and binge drinking in the United States. Alcohol Research: Current Reviews, 35(2), 193-200.

Peake, S. J., Dishion, T. J., Stormshak, E. A., Moore, W. E., \& Pfeifer, J. H. (2013). Risk-taking and social exclusion in adolescence: Neural mechanisms underlying peer influences on decision-making. Neurolmage, 82, 23-34.

Phinney, J. S., Madden, T., \& Santos, L. J. (1998). Psychological variables as predictors of perceived ethnic discrimination among minority and immigrant adolescents. Journal of Applied Social Psychology, 28(11), 937-953.

Portes, A., \& Puhrmann, A. (2015). A bifurcated enclave: The economic evolution of the Cuban and Cuban American population of metropolitan Miami. Cuban Studies, 43(1), 40-63.

Portes, A., \& Rumbaut, R. G. (2007). Children of Immigrants Longitudinal Study (CILS), 1991-2006. Ann Arbor, MI: Inter-university Consortium for Political and Social Research.

Prado, G., Szapocznik, J., Maldonado-Molina, M. M., Schwartz, S. J., \& Pantin, H. (2008). Drug use/abuse prevalence, etiology, prevention, and treatment in Hispanic adolescents: A cultural perspective. Journal of Drug Issues, 38(1), 5-36.

Puente, C. P., Gutierrez, J. L., Abellan, I. C., \& Lopez, A. L. (2008). Sensation seeking, attitudes toward drug use, and actual use among adolescents: Testing a model for alcohol and ecstasy use. Substance Use and Misuse, 43, 1615-1627.

Resnicow, K., Soler, R. E., Braithwaite, R. L., Selassie, M. B., \& Smith, M. (1999). Development of a racial and ethnic identity scale for African American adolescents: The survey of Black life. Journal of Black Psychology, 25(2), 171-188.

Rise, J., Sheeran, P., \& Hukkelberg, S. (2010). The role of self-identity in the theory of planned behavior: A meta-analysis. Journal of Applied Social Psychology, 40, 1085-1105.

Romero, A. J., Carvajal, S. C., Valle, F., \& Orduña, M. (2007). Adolescent bicultural stress and its impact on mental well-being among Latinos, Asian Americans, and European Americans. Journal of Community Psychology, 35(4), 519-534.

Romero, A. J., Martinez, D., \& Carvajal, S. C. (2007). Bicultural stress and adolescent risk behaviors in a community sample of Latinos and non-Latino European Americans. Ethnicity and Health, 12(5), 443-463.

Romero, A. J., \& Roberts, R. E. (2003). Stress within a bicultural context for adolescents of Mexican descent. Cultural Diversity and Ethnic Minority Psychology, 9, 171-184.

Rosenthal, D. A., Gurney, R. M., \& Moore, S. M. (1981). From trust on intimacy: A new inventory for examining Erikson's stages of psychosocial development. Journal of Youth and Adolescence, 10(6), 525-537. 
Salas-Wright, C. P., Clark, T. T., Vaughn, M. G., \& Córdova, D. (2015). Profiles of acculturation among Hispanics in the United States: Links with discrimination and substance use. Social Psychiatry and Psychiatric Epidemiology, 50(1), 39-49.

Schwartz, S. J., Beyers, W., Luyckx, K., Soenens, B., Zamboanga, B. L., Forthun, L. F., ... Waterman, A. S. (2011). Examining the light and dark sides of emerging adults' identity: A study of identity status differences in positive and negative psychosocial functioning. Journal of Youth and Adolescence, 40(7), 839-859.

Schwartz, S. J., Hardy, S. A., Zamboanga, B. L., Meca, A., Waterman, A. S., Picariello, S., .. Forthun, L. F. (2015). Identity in young adulthood: Links with mental health and risky behavior. Journal of Applied Developmental Psychology, 36, 39-52.

Schwartz, S. J., Mason, C. A., Pantin, H., \& Szapocznik, J. (2008). Effects of family functioning and identity confusion on substance use and sexual behavior in Hispanic immigrant early adolescents. Identity: An International Journal of Theory and Research, 8 , 107-124.

Schwartz, S. J., Mason, C. A., Pantin, H., \& Szapocznik, J. (2009). Longitudinal relationships between family functioning and identity development in Hispanic immigrant adolescents: Continuity and change. Journal of Early Adolescence, 29, 177-211.

Schwartz, S. J., Montgomery, M. J., \& Briones, E. (2006). The role of identity in acculturation among immigrant people: Theoretical propositions, empirical questions, and applied recommendations. Human Development, 49, 1-30.

Schwartz, S. J., Pantin, H., Prado, G., Sullivan, S., \& Szapocznik, J. (2005). Family functioning, identity, and problem behavior in Hispanic immigrant early adolescents. The Journal of Early Adolescence, 25(4), 392-420.

Schwartz, S. J., Unger, J. B., Baezconde-Garbanati, L., Zamboanga, B. L., Lorenzo-Blanco, E. I., Des Rosiers, S. E., ... Szapocznik, J. (2015). Trajectories of cultural stressors and effects on mental health and substance use among Hispanic immigrant adolescents. Journal of Adolescent Health, 56(4), 433-439.

Schwartz, S. J., Unger, J. B., Lorenzo-Blanco, E. I., Des Rosiers, S. E., Villamar, J. A., Pattarroyo, M., ... Szapocznik, J. (2014). Perceived context of reception among recent Hispanic immigrants: Conceptualization, instrument development, and preliminary validation. Cultural Diversity and Ethnic Minority Psychology, 20(1), 1-15.

Schwartz, S. J., Unger, J. B., Meca, A., Lorenzo-Blanco, E. I., Baezconde-Garbanati, L., Cano, M. A., ... Pattarroyo, M. (2017). Personal identity development in Hispanic immigrant adolescents: Links with positive psychosocial functioning, depressive symptoms, and externalizing problems. Journal of Youth and Adolescence, 46(4), 898-913.

Schwartz, S. J., Unger, J. B., Rosiers, S. E., Huang, S., Baezconde-Garbanati, L., Lorenzo-Blanco, E. I., ... Szapocznik, J. (2012). Substance use and sexual behavior among recent Hispanic immigrant' adolescents: Effects of parent-adolescent differential acculturation and communication. Drug and Alcohol Dependence, 125, S26-S34.

Schwartz, S. J., Unger, J. B., Zamboanga, B. L., \& Szapocznik, J. (2010). Rethinking the concept of acculturation. American Psychologist, 65, 237-251.

Schwartz, S. J., Zamboanga, B. L., Wang, W., \& Olthuis, J. V. (2009). Measuring identity from an Eriksonian perspective: Two sides of the same coin? Journal of Personality Assessment, 91, 143-154.

Schwartz, S. J., Zamboanga, B. L., Luyckx, K., Meca, A., \& Ritchie, R. A. (2013). Identity in emerging adulthood: Reviewing the field and looking forward. Emerging Adulthood, 1(2), 96-113.

Sherman, S. J., Chassin, L., Presson, C., Seo, D. C., \& Macy, J. T. (2009). The intergenerational transmission of implicit and explicit attitudes toward smoking: Predicting adolescent smoking initiation. Journal of Experimental Social Psychology, 45(2), 313-319.

Sireci, S. G., Yang, Y., Harter, J., \& Ehrlich, E. J. (2006). Evaluating guidelines for test adaptations: A methodological analysis of translation quality. Journal of Cross-Cultural Psychology, 37(5), 557-567.

Stepick, A., Grenier, G., Castro, M., \& Dunn, M. (2003). This land is our land: Immigrants and power in Miami. Berkeley, CA: University of California Press.

Stepick, A., \& Stepick, C. D. (2002). Power and identity: Miami Cubans. Latinos: Remaking America (pp. 75-92). Cambridge, MA: Harvard University Press.

Suárez-Orozco, C., Bang, H. J., \& Kim, H. Y. (2010). I felt like my heart was staying behind: Psychological implications of family separations \& reunifications for immigrant youth. Journal of Adolescent Research, 26, 222-257.

Szabo, A., \& Ward, C. (2015). Identity development during cultural transition: The role of social-cognitive identity processes. International Journal of Intercultural Relations, 46, 13-25.

Teruya, S. A., \& Bazargan-Hejazi, S. (2013). The immigrant and Hispanic paradoxes a systematic review of their predictions and effects. Hispanic Journal of Behavioral Sciences, 35(4), 486-509.

Tofighi, D., \& MacKinnon, D. P. (2011). RMediation: An R package for mediation analysis confidence intervals. Behavior Research Methods, 43(3), 692-700. 
Tran, A. G., Lee, R. M., \& Burgess, D. J. (2010). Perceived discrimination and substance use in Hispanic/Latino, African-born Black, and Southeast Asian immigrants. Cultural Diversity and Ethnic Minority Psychology, 16(2), 226-236.

Wei, M., Liao, K. Y. H., Chao, R. C. L., Mallinckrodt, B., Tsai, P. C., \& Botello-Zamarron, R. (2010). Minority stress, perceived bicultural competence, and depressive symptoms among ethnic minority college students. Journal of Counseling Psychology, 57(4), 411-422.

Zhou, M., \& Xiong, Y. S. (2005). The multifaceted American experiences of the children of Asian immigrants: Lessons for segmented assimilation. Ethnic and Racial Studies, 28(6), 1119-1152.

How to cite this article: Grigsby TJ, Forster M, Meca A, Zamboanga B, Schwartz SJ, Unger JB. Cultural stressors, identity development, and substance use attitudes among Hispanic immigrant adolescents. J Community Psychol. 2018;117-132. https://doi.org/10.1002/jcop.21920 